\title{
Experimental and Theoretical Investigation of Prestressed Natural Fiber- Reinforced Polylactic Acid (PLA) Composite Materials
}

\author{
S.A. Hinchcliffe ${ }^{\mathrm{a}}$, K.M. Hess ${ }^{\mathrm{a}}$, W.V. Srubar III ${ }^{\mathrm{a} \dagger}$ \\ ${ }^{a}$ Department of Civil, Environmental, and Architectural Engineering, University of Colorado Boulder, ECOT 441 \\ UCB 428, Boulder, Colorado 80309 USA, ${ }^{\dagger}$ Corresponding Author, T +1 303492 2621, E wsrubar@ @olorado.edu
}

\begin{abstract}
In this work we demonstrate that the specific mechanical properties of polylactic acid (PLA) can be enhanced by leveraging a combination of (a) additive manufacturing (3D printing) and (b) initial post-tensioning of continuous natural-fiber reinforcement. In this study both tensile and flexural PLA specimens with different crosssectional geometries were 3D-printed with and without post-tensioning ducts. The mechanical properties of two continuous reinforcing fiber strands (i.e., jute, flax) were experimentally characterized prior to threading, posttensioning to a prescribed level of stress, and securing in place with 3D-printed anchors. The effect of fiber type, matrix cross-sectional geometry, number of reinforcing strands, and degree of post-tensioning on the specific mechanical properties (i.e., strength-, stiffness-, rigidity-to-weight) of PLA were investigated using both tensile and flexural mechanical testing. Experimental results confirmed that additive manufacturing alone can improve the specific tensile and flexural mechanical properties of PLA and that these properties are further improved via initial mechanical prestressing of natural fiber reinforcement. Data indicate increases of $116 \%$ and $62 \%$ for tensile specific strength and stiffness and $12 \%$ and $10 \%$ for flexural specific strength and rigidity, respectively, compared to solid, unreinforced PLA. A theoretical model of the prestressed composite tensile response was employed and found to accurately predict (<10\% error) improvements in mechanical behavior.
\end{abstract}

Keywords: B. Mechanical Properties; D. Analytical Modeling; E.3-D Printing; Natural Fibers (nominated keyword). 1. Introduction

Polymers and composites from renewable resources are being engineered for target applications in the automotive, construction, and packaging industries at historically high rates to address growing environmental concerns of a globally unsustainable dependence on petroleum-based resources and to counter the proliferation of synthetic polymers and plastics in the environment. A variety of natural alternatives to synthetic fibers (e.g., carbon, glass, aramid) and petroleum-based polymers (e.g., polypropylene, polyethylene) have been evaluated for natural fiber- 
reinforced composite applications [1-7]. Previous work has focused primarily on material property characterization of isotropic, short-fiber composites made with natural fibers (e.g., hemp, flax, jute, sisal, henequen, wood) [8-12]. Investigations have also been carried out on pultruded hybrid specimens (not fully biobased) of hemp and continuous glass fibers [13] and woven jute, sisal, hemp, and flax [14]. Recently, woven hemp linen and jute burlap have been used as reinforcement in fully biobased composites with resins of poly(lactic acid) (PLA), poly(hydroxybutyrate) (PHB), and their copolymers [15-17].

The mechanical properties of these fully biobased composites vary widely with many achieving properties similar to (or exceeding) wood and engineered wood products [18-22]. For example, Christian and Billington [15] reported an average flexural strength and flexural modulus of $65 \mathrm{MPa}$ and $6500 \mathrm{MPa}$, respectively, for a hemp fiberreinforced PHB composite. In comparison, the flexural strengths and flexural moduli of plywood and pine are approximately $27 \mathrm{MPa}$ and 40-55 MPa and $10000 \mathrm{MPa}$ and $9000 \mathrm{MPa}$, respectively [15]. The relative densities of biobased composites, however, can be three times the density of wood or engineered wood materials. For example, the hemp fiber-reinforced PHB composite reported by Christian and Billington exhibited a density of 1270-1310 $\mathrm{kg} / \mathrm{m}^{3}$, whereas plywood and pine have densities of $400-810 \mathrm{~kg} / \mathrm{m}^{3}$ and $450 \mathrm{~kg} / \mathrm{m}^{3}$, respectively $[10,23]$.

Natural fibers from plants and animals exhibit good tensile mechanical properties (e.g., strength, stiffness), adding to other positive environmental and economic attributes such as low cost, rapid renewability, and worldwide availability $[3,6,18,19]$. When natural fibers are incorporated into a high-density polymer-matrix composite, however, the overall composite may have reduced specific (weight-normalized) properties in comparison to the individual constituents. For example, hemp fiber has a tensile strength between 600 and $900 \mathrm{MPa}$, while reported hemp fiber-reinforced composites exhibit an average tensile strength of only $56 \mathrm{MPa}$ [10,23-25], thus demonstrating that the high specific mechanical properties of natural fibers may not be fully utilized in traditional composite form.

\subsection{Potential for prestressed natural fiber composites (NFCs)}

Previous research has shown that reductions in density and improvements in specific mechanical properties of highdensity biopolymers and NFCs can be achieved by foaming [26,27] and engineering foam-core sandwich structures [18]. Past studies have also investigated the effect of fiber prestressing on the mechanical behavior of synthetic fibers, namely glass [28], ultra-high molecular weight polyethylene [29], and nylon-kevlar [30] fiber composites. In previous ply- and laminate-level studies of synthetic FRPs, Motahhari and Cameron [28] found that the flexural modulus and strength of glass-epoxy composites increased 33\% through initial fiber prestressing. The experimental 
data also indicated a fiber prestressing level (50\% of ultimate stress) at which flexural properties reached maximum values. Similarly, another study demonstrated that prestressing unidirectional glass fibers increases the flexural deflection and strength of polymer-based dental resins by $60 \%$ and $30 \%$, respectively [31].

Given the proven success of prestressing synthetic fibers [32-34], the high stiffness and strength of natural fibers, and the ability of additive manufacturing to form complex, structural geometries, a potential exists to improve the specific mechanical properties of NFCs through a combination of 3D printing and natural fiber post-tensioning, particularly for high-density polymers with higher ultimate strengths in compression than tension. However, to the authors' knowledge, the feasibility of prestressing natural fibers for high-performance NFCs has neither been experimentally nor theoretically substantiated.

\subsection{Scope of work}

The objective of this study was to demonstrate that the specific mechanical properties of high-density biopolymers (i.e., PLA) and natural-fiber composites thereof can be improved by (a) leveraging additive manufacturing (3D printing) capabilities and (b) applying a prestressing technique to the continuous natural fiber reinforcement. In this work, the ultimate tensile strength and stiffness of both jute and flax continuous fiber strands were first characterized via mechanical testing. Tension and flexural PLA specimens were then 3D printed with and without post-tensioning ducts. Fiber strands were then threaded through the ducts, stressed to prescribed levels of pretensioning, and affixed into place using 3D-printed anchors. The specific (weight-normalized) tensile and flexural mechanical properties of solid PLA composites were then characterized and compared to samples with and without initial fiber prestressing. Finally, experimental mechanical results of both fibers and the PLA matrix were used to validate a theoretical model that was derived to predict the specific tensile mechanical strength and stiffness properties of the prestressed NFCs.

\section{Materials and methods}

\section{$2.1 \quad$ Materials}

Polylactic acid (PLA) was supplied in filament form (1.8 mm diameter) by MakerBot Industries, LLC. The PLA filament was reported to have a tensile strength of $66 \mathrm{MPa}$, a compressive strength of $94 \mathrm{MPa}$, a glass transition temperature $\left(T_{\mathrm{g}}\right)$ of $60-65^{\circ} \mathrm{C}$, and a melting temperature $\left(T_{\mathrm{m}}\right)$ of $150-160^{\circ} \mathrm{C}$. Natural jute and flax fiber strands were commercially obtained from a local hardware supply store. The continuous jute fiber strands consisted of five small bundles of approximately 100 individual fibers loosely spun into one strand (2.0 $\mathrm{mm}$ diameter). The continuous flax fiber strands consisted of 4 small bundles of approximately 30 individual fibers tightly spun into one strand $(0.5 \mathrm{~mm}$ diameter). The ambient moisture contents of the jute and flax fiber strands were $9.7 \%$ and $11.3 \%$, respectively. 


\subsection{Experimental methods}

\subsubsection{Tensile specimen manufacture}

PLA tensile dogbone specimens were computer-modeled according to the required geometry outlined in ASTM D638 and 3D-printed using a MakerBot $5^{\text {th }}$-Generation Replicator Desktop 3D printer. As suggested by the manufacturer, the extruder temperature, resolution, and print speed were set to $215^{\circ} \mathrm{C}, 0.2 \mathrm{~mm}$, and $60 \mathrm{~mm} / \mathrm{s}$, respectively, for the PLA filament. Specimens were printed in a room-temperature environment at ambient-humidity conditions. Two types of cross-sectional geometries were considered for the tensile specimens: (a) solid crosssections $(5 \mathrm{~mm} \times 15 \mathrm{~mm})$ and (b) cross-sections $(5 \mathrm{~mm} \times 15 \mathrm{~mm})$ containing three (3) equally spaced $3 \mathrm{~mm}$ diameter post-tensioning ducts. The specimens were 3D-printed in an orientation that created individual layers parallel to the longitudinal axial direction of each specimen. The 3D-printing process required approximately four (4) hours for each tensile specimen. A summary of the six (6) classes of tensile specimens is presented in Table 1.

One (1) class of jute-reinforced specimens was prepared (T-J1) using a fiber prestress level of $50 \%$ of the ultimate fiber tensile strength, $\sigma_{\mathrm{u}}$. Due to size limitations, one (1) jute fiber strand per duct (3 total strands) was used for the T-J1 specimens. Three (3) classes of flax-reinforced specimens were considered. Six (6) flax fiber strands per duct (18 total strands) were used for the first (T-F1) $\left(25 \% \sigma_{\mathrm{u}}\right)$ and second class (T-F2) $\left(50 \% \sigma_{\mathrm{u}}\right)$ and eight (8) flax fiber strands per duct (24 total strands) for the third class (T-F3) $\left(50 \% \sigma_{\mathrm{u}}\right)$ of flax-reinforced specimens. After threading the fiber strands through the ducts and anchoring one end with a knot, the fiber strands were posttensioned using an Instron 5869 Universal Testing Machine. One end of the dogbone specimens was affixed in the machine grips, while the fiber strands on the free end were fixed in the opposite grip. After pre-tensioning the fiber strands, the machine was paused so that 3D-printed anchors could be fitted to the free end of the specimen. Since the fiber strands remain unbonded to the PLA inside the ducts, these anchors ensured that the fiber strands are in their initial stressed state in order to reduce loss of prestressing force in the fiber reinforcement once the mechanical force was released from the fiber reinforcement.

Table 1. Tensile specimen summary indicating geometry, reinforcement type, and prescribed post-tensioning.

\begin{tabular}{ccccccc}
\hline $\begin{array}{c}\text { Specimen } \\
\text { Nomenclature }\end{array}$ & Cross-section & $\begin{array}{c}\text { Number of } \\
\text { ducts }\end{array}$ & $\begin{array}{c}\text { Reinforcement } \\
\text { fiber }\end{array}$ & $\begin{array}{c}\text { Number of fiber } \\
\text { strands per duct }\end{array}$ & $\begin{array}{c}\text { Number of fiber } \\
\text { strands }\end{array}$ & $\begin{array}{c}\text { Post-tension force } \\
\left(\mathbf{N}, \boldsymbol{\%} \boldsymbol{\sigma}_{\mathbf{u}}\right)\end{array}$ \\
\hline T-S1 & Solid rectangle & 0 & None & 0 & 0 & 0 \\
T-U1 & Ducted rectangle & 3 & None & 0 & 0 & 0 \\
T-J1 & Ducted rectangle & 3 & Jute & 1 & 3 & $400 \mathrm{~N}, 50 \%$ \\
T-F1 & Ducted rectangle & 3 & Flax & 6 & 18 & $275 \mathrm{~N}, 25 \%$ \\
T-F2 & Ducted rectangle & 3 & Flax & 6 & 18 & $550 \mathrm{~N}, 50 \%$ \\
T-F3 & Ducted rectangle & 3 & Flax & 8 & 24 & $730 \mathrm{~N}, 50 \%$ \\
\hline
\end{tabular}




\subsubsection{Flexural specimen manufacture}

Similarly, flexural PLA matrices (I-beams) were computer-modeled and 3D-printed using a MakerBot $5^{\text {th }}$ Generation Replicator Desktop 3D printer. As suggested by the manufacturer, the extruder temperature, resolution, and print speed were set to $215^{\circ} \mathrm{C}, 0.2 \mathrm{~mm}$, and $60 \mathrm{~mm} / \mathrm{s}$, respectively, for the PLA filament. Specimens were printed in a room-temperature environment at ambient-humidity conditions. The specimens were 3D-printed in an orientation that created layers of PLA parallel to the longitudinal axial direction of each specimen. The 3D-printing process required approximately eight (8) hours for each flexural specimen.

The four (4) classes of flexural specimens are summarized in Table 2. All specimens were designed to have similar ducted I-shape cross-sectional geometries to isolate improvements in mechanical properties from fiber prestressing alone, rather than changes in cross-sectional geometry. The I-beam cross-sections had nominal depths of $25 \mathrm{~mm}$, widths of $15 \mathrm{~mm}$, and $5 \mathrm{~mm}$ flange and web thicknesses. Post-tensioning ducts were $3 \mathrm{~mm}$ in diameter. The total length of the flexural specimens was $190 \mathrm{~mm}$. After 3D printing, the same fiber strand threading, prestressing, and anchoring technique used to fabricate the tensile specimens was employed. The prestressing technique for flexural beam specimens is shown schematically in Figure 1, along with examples of the resulting 3Dprinted flexural specimens with and without fiber reinforcement. First, the PLA I-beam matrices were 3D-printed with smooth, continuous post-tensioning ducts. Then, the fibers were threaded through the ducts, anchored on one end, post-tensioned to a prescribed level of stress, and anchored into place without adhesive bonding between the ducts and fiber strands. Finally, the fibers were released, resulting in NFCs in an initially compressed stress state.
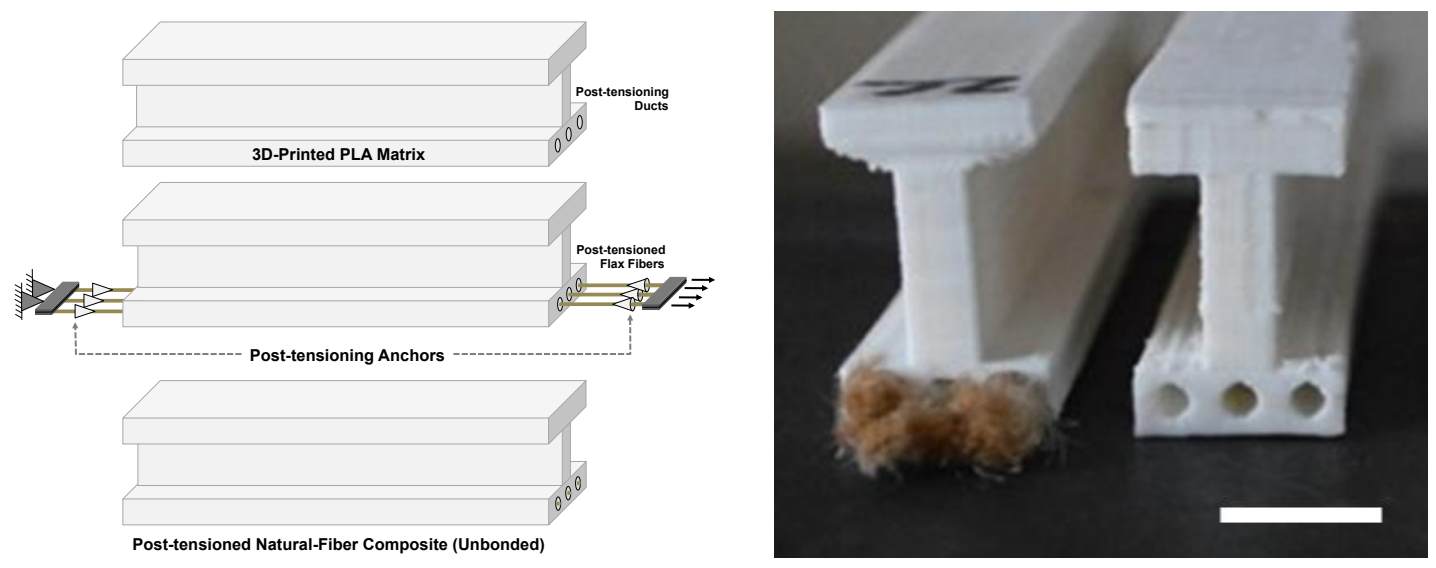

Figure 1. (a) Schematic of the fiber post-tensioning process and (b) 3D-printed NFC flexural specimen with (left) and without fiber reinforcement (right). Scale bar $=1 \mathrm{~cm}$.

As shown in Table 2, two (2) classes of flax-reinforced I-beam specimens (8 strands per duct) were stressed to prescribed fiber prestress levels of 25\% (F-F1) and 50\% (F-F2) of the fiber ultimate tensile strength. 
Table 2. Flexure specimen summary indicating levels of prescribed fiber post-tensioning. Flax fiber reinforcing strands consisted of continuous, bundled yarns.

\begin{tabular}{ccccccc}
\hline $\begin{array}{l}\text { Specimen } \\
\text { Nomenclature }\end{array}$ & Cross-section & $\begin{array}{c}\text { Number of } \\
\text { ducts }\end{array}$ & $\begin{array}{c}\text { Reinforcement } \\
\text { fiber }\end{array}$ & $\begin{array}{c}\text { Number of fiber } \\
\text { strands per duct }\end{array}$ & $\begin{array}{c}\text { Number of fiber } \\
\text { strands } \\
\text { per specimen }\end{array}$ & $\begin{array}{c}\text { Post-tension force } \\
\left(\mathbf{N}, \boldsymbol{\%} \boldsymbol{\sigma}_{\mathbf{u}}\right)\end{array}$ \\
\hline F-S1 & Solid I-shape & 0 & None & 0 & 0 & 0 \\
F-U1 & Ducted I-shape & 3 & None & 0 & 0 & 0 \\
F-F1 & Ducted I-shape & 3 & Flax & 8 & 24 & $365 \mathrm{~N}, 25 \%$ \\
F-F2 & Ducted I-shape & 3 & Flax & 8 & 24 & $730 \mathrm{~N}, 50 \%$ \\
\hline
\end{tabular}

\subsubsection{Mechanical Characterization}

\subsubsection{Natural fiber tensile mechanical properties}

To determine appropriate force (and stress) levels for fiber prestressing, single fiber-strand tensile tests were conducted according to a modified ASTM D2256 using an Instron 5869 Universal Testing Machine to characterize the bulk tensile strength and stiffness of individual jute and flax fiber constituents. Five (5) samples of jute and flax fiber strands were tested at a displacement-controlled rate of $0.1 \mathrm{~mm} / \mathrm{s}$. Details on calculating the ultimate fiber tensile strength and tensile stiffness (modulus) of each fiber sample have been reported elsewhere [20].

\subsubsection{PLA compressive mechanical properties}

Given that differences often exist between reported and actual mechanical properties of commercial biopolymers [35], compression tests were conducted to characterize the compression mechanical properties of PLA. Five (5) nonslender, rectangular prisms of PLA with dimensions 12.7 x 12.7 × $25.4 \mathrm{~mm}$ were 3D-printed using the same settings as previously described and tested to failure using an Instron 5869 Universal Testing Machine in accordance with ASTM D695 using a displacement-controlled rate of $0.025 \mathrm{~mm} / \mathrm{s}$. The matrix compressive strength, $\sigma_{m}$ (MPa) was determined by dividing the peak compressive force, $P_{\max }(\mathrm{N})$, by the original cross-sectional area, $A\left(\mathrm{~mm}^{2}\right)$.

\subsubsection{Unstressed and prestressed NFC tensile mechanical properties}

All tensile composite specimens were tested using an Instron 5869 Universal Testing Machine using a displacementcontrolled rate of $0.05 \mathrm{~mm} / \mathrm{s}$. Each specimen was tested in triplicate. The strength and modulus were calculated for each tensile specimen, from which strength- and stiffness-to-weight ratios (i.e., tensile mechanical properties normalized by specimen weight) were determined.

The tensile strength-to-weight ratio, $\sigma^{\prime}{ }_{t}(\mathrm{MPa} / \mathrm{g})$, of each specimen was determined by dividing the peak tensile force, $P_{\max }(\mathrm{N})$, by both the cross sectional area, $A\left(\mathrm{~mm}^{2}\right)$, and the specimen weight, $W(\mathrm{~g})$. The tensile stiffness-toweight ratio, $E_{t}^{\prime}(\mathrm{MPa} / \mathrm{g})$ for each tensile specimen was calculated by dividing the initial slope of the force displacement curve between $10 \%$ and $40 \%$ of the ultimate peak load, $C(\mathrm{~N} / \mathrm{mm})$ and the extensometer gauge length, 
$L(\mathrm{~mm})$, by both the cross sectional area, $A\left(\mathrm{~mm}^{2}\right)$, and the specimen weight, $W(\mathrm{~g})$. The range of $C$ was chosen to consistently define the elastic regime for all composite samples investigated herein.

\subsubsection{Unstressed and prestressed NFC flexural mechanical properties}

All flexural composite specimens were tested in three-point bending with a span length of $160 \mathrm{~mm}$ and a displacement-controlled rate of $0.05 \mathrm{~mm} / \mathrm{s}$ using an Instron 5869 Universal Testing Machine. Each specimen was tested in triplicate. The flexural strength of the specimens was calculated based on the method of transformed sections, which is commonly implemented for prestressed reinforced concrete sections and outlined in the Precast Concrete Institute (PCI) Design Handbook [36]. A graphical representation of the flexural stress distribution that occurs within the cross-section of the prestressed NFC flexural specimens is shown in Figure 2.

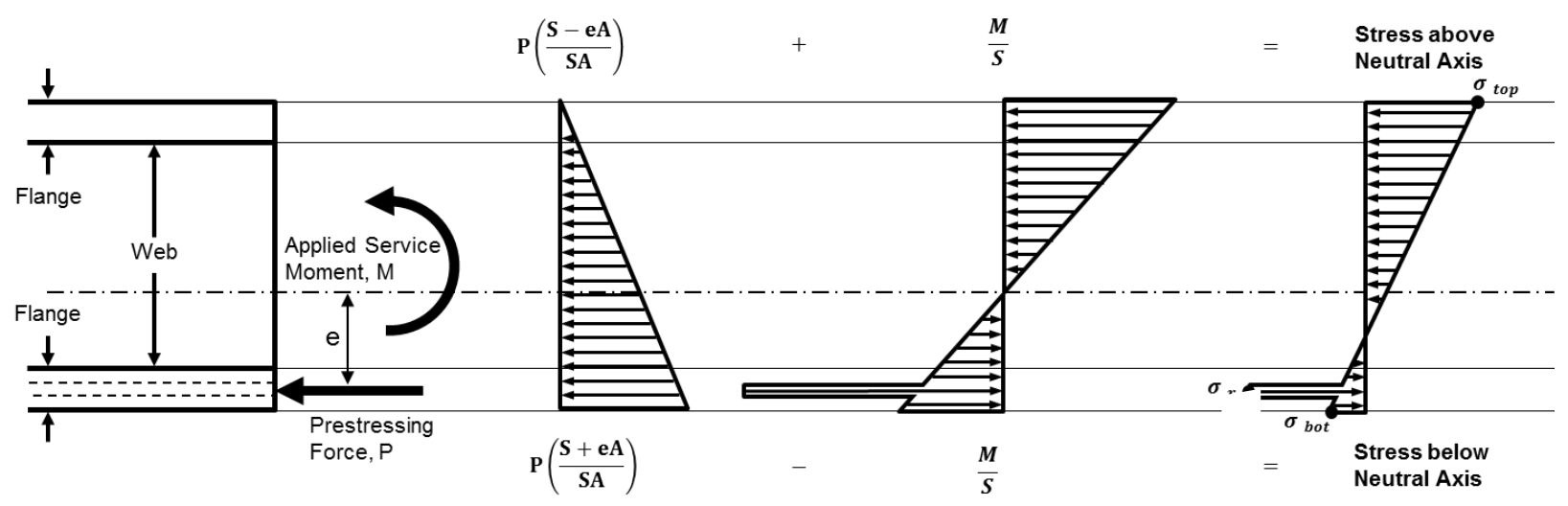

Figure 2. Graphic representation of the stress distribution in prestressed natural-fiber composite beams.

The flexural stresses in the top edge, $\sigma_{t o p}$, bottom edge, $\sigma_{b o t}$, and fiber reinforcement, $\sigma_{r}$, were determined according to the following equations:

$$
\begin{gathered}
\sigma_{\text {top }}=P\left(\frac{S-e A}{S A}\right)+\frac{M}{S} \\
\sigma_{b o t}=P\left(\frac{S+e A}{S A}\right)-\frac{M}{S} \\
\sigma_{r}=n\left(P\left(\frac{S+e A}{S A}\right)-\frac{M}{S}\right)
\end{gathered}
$$

where:

$$
M=\frac{P_{\max } L}{4} \quad \text { and } \quad S=\frac{I_{t}}{y}
$$

in three-point bending and where $P$ is the prestress force applied to the fiber reinforcement, $e$ is the distance from the center of the reinforcement to the neutral axis of the cross section, $M$ is the maximum applied moment, $P_{\max }$ is the maximum load from the flexure test, $L$ is the $160 \mathrm{~mm}$ span length, and $S$ is the section modulus, defined as the 
ratio of the transformed moment of inertia, $I_{t}$, and the distance from the desired location to the neutral axis, $y$. The modular ratio, $n$, is the ratio of the elastic moduli of the fiber, $E_{f}$, and PLA matrix, $E_{m}$.

The experimentally obtained flexural rigidity, $E I_{\mathrm{f}}$, for each sample was calculated according to:

$$
E I_{f}=\frac{C L^{3}}{48}
$$

Where $C$ is the slope of a linear regression based on the load-displacement data between $10 \%$ and $40 \%$ of the maximum applied load and corresponding displacement. The flexural strength-to-weight ratio, $\sigma_{f}{ }^{\prime}$, and rigidity-toweight ratio, $E I_{f}{ }^{\prime}$, were calculated according to:

$$
\begin{aligned}
& \sigma_{f}{ }^{\prime}=\frac{\sigma_{t o p}}{W} \\
& E I_{f}{ }^{\prime}=\frac{E I_{f}}{W}
\end{aligned}
$$

where $W$ is specimen weight $(\mathrm{g})$.

\subsection{Theoretical modeling}

Predictive analytical equations for tensile strength- and stiffness-to-weight ratio were derived using the variables shown in Table 3.

Table 3. Summary of input variables for derivation of theoretical model for predicting the specific tensile mechanical properties of prestressed NFCs.

\begin{tabular}{ccl}
\hline Variable & Unit & \multicolumn{1}{c}{ Description } \\
\hline$F$ & $\mathrm{~N}$ & Externally applied composite tensile force \\
$F_{u}$ & $\mathrm{~N}$ & Ultimate composite tensile force \\
$\sigma_{m}$ & $\mathrm{MPa}$ & Applied tensile stress in matrix \\
$\sigma_{m u}$ & $\mathrm{MPa}$ & Ultimate tensile strength of matrix \\
$A_{m}$ & $\mathrm{~mm}^{2}$ & Net cross-sectional area of matrix \\
$E_{m}$ & $\mathrm{MPa}$ & Tensile modulus of matrix \\
$\sigma_{f}$ & $\mathrm{MPa}$ & Applied tensile stress in fiber \\
$\sigma_{f u}$ & $\mathrm{MPa}$ & Ultimate tensile strength of fiber \\
$A_{f}$ & $\mathrm{~mm}$ & Total area of fiber reinforcement \\
$d$ & $\mathrm{~mm}$ & Diameter of single fiber \\
$E_{f}$ & $\mathrm{MPa}$ & Tensile modulus of fiber \\
$k$ & - & Number of fiber strands in cross-section \\
$W$ & $\mathrm{~g}$ & Specimen weight \\
$F_{p}$ & $\mathrm{~N}$ & Initial fiber prestressing force \\
$F_{e}$ & $\mathrm{~N}$ & Equilibrium prestressing force \\
\hline
\end{tabular}

The mathematical prediction of tensile strength-to-weight ratio was derived from first-principles of force equilibrium. The applied tensile load, $F$, can be expressed in terms of the force in the matrix, force in the fiber strands, and the equilibrium force, $F_{e}$, due to initial fiber prestressing:

$$
F=\sigma_{m} A_{m}+\sigma_{f} A_{f}+F_{e}
$$


The derivation included the following assumptions: (1) matrix failure occurs first (which was experimentally observed), (2) fibers are circular in geometry, (3) both fiber and matrix materials behave perfectly elastically, and (4) both matrix and fiber reinforcement experience equal strain at failure. Thus, assuming equal strain at failure and linear elasticity (Hooke's law) for both fiber and matrix yields:

$$
\frac{\sigma_{f u}}{E_{f}}=\frac{\sigma_{m u}}{E_{m}}
$$

Thus, the ultimate composite tensile load, $F_{u}$, can be expressed as:

$$
F_{u}=\sigma_{m u} A_{m}+\sigma_{m u}\left(\frac{k \pi d^{2}}{4}\right) \frac{E_{f}}{E_{m}}+F_{e}
$$

where the quantity in brackets is equal to the total area of natural fiber reinforcement, $A_{\mathrm{f}}$ -

To determine the equilibrium force $\left(F_{e}\right)$ resulting from the initial fiber prestressing force $\left(F_{p}\right)$, first, the initial strain in the fiber after initial prestressing, $\varepsilon_{f i}$, was calculated according to the following equation:

$$
\varepsilon_{f i}=\frac{4 F_{p}}{k \pi d^{2} E_{f}}
$$

from which the equilibrium force between the matrix and prestressed fiber strands after release (resulting from elastic shortening) can be determined:

$$
F_{e}=\frac{4 F_{p}}{k \pi d^{2} E_{f}} \cdot\left[\frac{4}{k \pi d^{2} E_{f}}+\frac{1}{A_{m} E_{m}}\right]^{-1}
$$

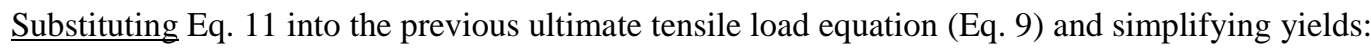

$$
F_{u}=\sigma_{m u}\left(A_{m}+\frac{k \pi d^{2}}{4} \frac{E_{f}}{E_{m}}\right)+F_{p}\left(1+\frac{k \pi d^{2}}{4 A_{m}} \frac{E_{f}}{E_{m}}\right)^{-1}
$$

Normalizing Eq. 12 by cross-sectional area and dividing by specimen weight gives the equations for composite tensile strength-to-weight ratio, $\sigma_{t}^{\prime}$ :

$$
\sigma_{t}^{\prime}=\frac{\sigma_{c}}{\mathrm{~W}}=\frac{\sigma_{m u}}{W}\left(1+\frac{k \pi d^{2}}{4 A_{m}} \frac{E_{f}}{E_{m}}\right)+F_{p}\left[W\left(A_{m}+\frac{k \pi d^{2}}{4} \frac{E_{f}}{E_{m}}\right)\right]^{-1}
$$

Employing a simple isostrain rule-of-mixtures (Voigt model), the effective composite tensile modulus, $E_{\text {eff }}$, can be computed by:

$$
E_{e f f}=\frac{A_{m} E_{m}+A_{f} E_{f}}{A_{m}+A_{f}}
$$

Normalizing by specimen weight and substituting the equation for total area of fiber reinforcement, $A_{\mathrm{f}}$, the composite tensile stiffness-to-weight ratio, $E_{t}{ }_{t}$, is expressed as:

$$
E_{t}^{\prime}=\frac{E_{e f f}}{W}=\left[A_{m} E_{m}+\frac{k \pi d^{2}}{4} E_{f}\right] \cdot\left[W\left(A_{m}+\frac{k \pi d^{2}}{4}\right)\right]^{-1}
$$


Manuscript Submitted to:

Composites Part B: Engineering

\section{Experimental and Theoretical Results}

\subsection{Constituent Mechanical properties}

Mechanical property (i.e., tensile strength, tensile stiffness) results from the single fiber strand tensile tests for jute and flax and the compressive test for PLA are shown in Table 4. As expected, the results illustrate that the tightly wound continuous flax fiber strands were stronger and stiffer than the loosely bound jute fiber strands. On average, the tensile strength and tensile stiffness of the jute fiber strands were $75.0 \mathrm{MPa}$ and $4375 \mathrm{MPa}$, respectively, compared to $266.1 \mathrm{MPa}$ and $17285 \mathrm{MPa}$ for the flax fiber strands. As anticipated, large variations were exhibited, particularly for the flax fiber strands, which can be attributed to a variety of growth and processing parameters, including fiber chemistry, size, moisture content, and treatments [37]. Given that the flax fiber strands were, on average, stronger and stiffer than the jute fiber strands, it was hypothesized that flax would be more effective in a prestressed-fiber composite application where high tensile strengths are required.

Table 4. Constituent mechanical properties.

\begin{tabular}{c|c|cc}
\hline \multirow{2}{*}{ Property } & Matrix & \multicolumn{2}{|c}{ Reinforcement } \\
\cline { 2 - 4 } & $P L A$ & Jute & Flax \\
\hline Tensile Strength (MPa) & $37.4 \pm 7.2$ & $75.0 \pm 10.3$ & $266.1 \pm 91.4$ \\
Modulus of Elasticity (MPa) & $3053 \pm 112$ & $4375 \pm 373$ & $17285 \pm 2442$ \\
Compressive Strength (MPa) & $66.0 \pm 1.1$ & - & - \\
\hline
\end{tabular}

The computed average compressive strength of the solid PLA specimens was 66.0 MPa. An initial comparison of this result with the average tensile strengths obtained for the solid cross-section tensile specimens (see Section 3.2) indicated that this particular PLA matrix material was $76 \%$ stronger in compression than in tension, thus rendering it a good candidate for improved mechanical behavior via initial fiber prestressing.

\subsection{Tensile properties of prestressed NFCs}

Representative tensile stress-strain relationships of the unreinforced (T-U1), 25\% prestressed flax (six (6) fiber strands per duct) (T-F1), and 50\% prestressed flax (eight (8) strands per duct) (T-F3) tensile specimens are shown in Figure 3. The stress-strain behaviors demonstrate increases in ultimate tensile strength and stiffness with the incorporation of prestressed flax fiber strands from the unreinforced case (i.e., T-U1 vs. T-F1). Furthermore, it is evident from these representative stress-strain behaviors that ultimate tensile strength and stiffness are further improved with additional fiber reinforcing strands and higher levels of prestressing (i.e., T-F1 vs. T-F3). All specimens indicated a failure mode of brittle fracture of the matrix, where the matrix failed in tension before the fibers ruptured. The mode of failure suggests that the prescribed level of prestressing for all composites could be further increased, which may lead to additional improvements in ultimate strength and stiffness. 


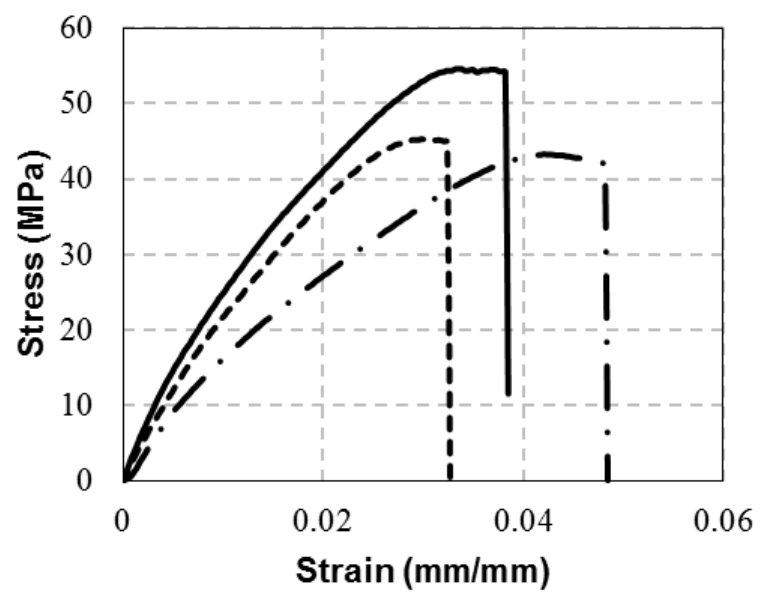

Figure 3. Representative tensile stress-strain relationships for T-U1 ( • -), T-F1 ( $~-)$, and T-F3 (一) composite specimens.

Ultimate tensile strength, tensile modulus, tensile strength-to-weight ratio $\left(\sigma_{\mathrm{t}}^{\prime}\right)$, tensile stiffness-to-weight ratio $\left(E_{\mathrm{t}}^{\prime}\right)$, and percent $(\%)$ increase from the solid, unreinforced PLA sample (T-S1) are presented in Table 5 for all unstressed and prestressed tensile specimens. The data indicate that all of the ducted sections (with and without fiber strands) result in higher specific properties than the solid PLA sample (T-S1). For example, the increase in $\sigma_{t}^{\prime}$ and $E_{\mathrm{t}}{ }_{\mathrm{t}}$ from T-S1 to the unreinforced ducted cross-section (T-U1) was approximately $64 \%$ and $30 \%$, respectively.

Table 5. Average specific tensile mechanical properties of solid (T-S1), unreinforced (T-U1) and prestressed jute and flax natural fiber-reinforced PLA composites.

\begin{tabular}{|c|c|c|c|c|c|c|}
\hline \multirow{2}{*}{ Property } & \multicolumn{6}{|c|}{ Tensile Specimen } \\
\hline & T-S1 & T-U1 & T-J1 & T-F1 & T-F2 & T-F3 \\
\hline Cross Sectional Geometry & & 000 & 000 & 000 & 000 & 000 \\
\hline Tensile Strength, $\sigma(\mathrm{MPa})$ & $37.4 \pm 7.2$ & $38.8 \pm 6.4$ & $40.8 \pm 4.3$ & $49.7 \pm 2.0$ & $46.4 \pm 2.1$ & $56.3 \pm 0.7$ \\
\hline Modulus of Elasticity, $E$ (MPa) & $3053 \pm 112$ & $2499 \pm 431$ & $2613 \pm 506$ & $3145 \pm 144$ & $2941 \pm 300$ & $3457 \pm 371$ \\
\hline$\sigma_{\mathrm{t}}^{\prime}(\mathrm{MPa} / \mathrm{g})$ & $2.25 \pm 0.39$ & $3.70 \pm 0.49$ & $3.74 \pm 0.82$ & $4.31 \pm 0.18$ & $4.55 \pm 0.38$ & $4.85 \pm 0.06$ \\
\hline$\%$ Increase $\left(\sigma_{\mathrm{t}}^{\prime}\right)$ & -- & $64 \%$ & $66 \%$ & $92 \%$ & $102 \%$ & $116 \%$ \\
\hline$E_{\mathrm{t}}^{\prime}(\mathrm{MPa} / \mathrm{g})$ & $184 \pm 10$ & $239 \pm 35$ & $235 \pm 42$ & $273 \pm 14$ & $288 \pm 37$ & $298 \pm 32$ \\
\hline$\%$ Increase $\left(\mathrm{E}_{\mathrm{t}}^{\prime}\right)$ & -- & $30 \%$ & $27 \%$ & $48 \%$ & $57 \%$ & $62 \%$ \\
\hline
\end{tabular}

Improvements in specific properties can be observed between the unreinforced specimens (T-U1) to the prestressed jute- (T-J1) and flax-reinforced specimens (T-F1, T-F2, T-F3). As anticipated, the jute-reinforced specimens (T-J1) did not show as significant improvements in specific properties over the unreinforced case (T-U1) compared to the flax-reinforced composites. However, the T-F3 samples exhibited the highest increases in $\sigma_{\mathrm{t}}^{\text {' }}$ 
(116\%) and $E_{\mathrm{t}}^{\prime}(62 \%)$ in comparison to the solid PLA specimens (T-S1). The flax-reinforced specimens (T-F3) also showed a maximum increase in $\sigma_{\mathrm{t}}^{\prime}$ over the unreinforced ducted specimens (T-U1) from $3.70 \mathrm{MPa} / \mathrm{g}$ to $4.85 \mathrm{MPa} / \mathrm{g}$ and in $E_{\mathrm{t}}$, from $239 \mathrm{MPa} / \mathrm{g}$ to $298 \mathrm{MPa} / \mathrm{g}$. These results suggest that the increase in mechanical properties may be attributed not only to cross-sectional geometry (e.g., solid or ducted) but also to additional fiber prestressing. In addition to all of the samples exhibiting statistically significant increases in both $\sigma_{\mathrm{t}}^{\prime}$ and $E_{\mathrm{t}}^{\prime}$ compared to T-S1, an analysis of variance (ANOVA) confirmed that increases in $\sigma_{\mathrm{t}}^{\prime}$ and $E_{\mathrm{t}}^{\prime}$ from the unreinforced case (T-U1) for flaxreinforced specimen groups T-F2 and T-F3 are statistically significant ( $p$-value $<0.05)$.

\subsection{Flexural properties of prestressed NFCs}

The results from the flexural mechanical tests of the solid, unreinforced, and prestressed flax-fiber composite Ibeams are shown in Table 6. Similar to the tensile mechanical data, the results indicate that $50 \%$ prestressed flaxreinforced specimens (F-F2) exhibited the greatest increase in specific flexural strength $\left(\sigma_{\mathrm{f}}^{\prime}\right)$ and specific flexural rigidity $\left(E I_{\mathrm{f}}^{\prime}\right)$ compared to the unreinforced case (F-U1), which can be attributed to higher levels of prestressing. The improvements due to prestressing can be observed from the increase in flexural properties when comparing the F-F1 (25\% prestressing) and F-F2 (50\% prestressing) specimens. The flexural strength increased by 11\%, 14\%, and $14 \%$ in the top edge, bottom edge, and reinforcement, respectively, and the flexural rigidity increased by $12 \%$. The 50\% prestressed flax-reinforced (F-F2) specimens also demonstrated improved specific properties when compared to the unreinforced (F-U1) and solid (F-S1) specimens. The F-F2 specimens exhibited 10\% and 12\% increases in strength-to-weight ratios and 9\% and 10\% increases in rigidity-to-weight ratios when compared to F-U1 and F-S1 specimens, respectively. The results indicate that (1) the cross-sectional geometry (e.g., solid or ducted) can reduce the weight of the samples without compromising the flexural capacity and (2) increasing the degree of fiber prestressing can improve the specific flexural properties of natural fiber reinforced PLA specimens.

Table 6. Average flexural mechanical property comparisons between the solid (F-I-S1), unreinforced (F-I-U1) and prestressed flax natural fiber-reinforced PLA composites.

\begin{tabular}{|c|c|c|c|c|c|c|c|c|}
\hline \multirow{3}{*}{ Specimen } & \multicolumn{4}{|c|}{ Flexural Mechanical Properties } & \multicolumn{4}{|c|}{ Specific Flexural Mechanical Properties } \\
\hline & \multicolumn{3}{|c|}{ Strength (Mpa) } & \multirow{2}{*}{$\begin{array}{c}\text { Rigidity, EI } \\
\left(\mathrm{N}-\mathrm{m}^{2}\right)\end{array}$} & \multirow{2}{*}{$\begin{array}{c}\boldsymbol{\sigma}_{\mathrm{f}} \\
(\mathrm{MPa} / \mathrm{g})\end{array}$} & \multirow{2}{*}{$\begin{array}{c}\% \\
\text { Increase } \\
\left(\sigma_{f}^{\prime}\right)\end{array}$} & \multirow{2}{*}{$\begin{array}{c}\mathbf{E I}_{\mathbf{f}}^{\prime} \\
\left(\mathbf{N}-\mathbf{m}^{2} / \mathbf{g}\right)\end{array}$} & \multirow{2}{*}{$\begin{array}{c}\% \\
\text { Increase } \\
\left(\text { EI' }_{\mathbf{f}}\right)\end{array}$} \\
\hline & $\sigma_{\text {top }}$ & $\sigma_{b o t}$ & $\sigma_{r}$ & & & & & \\
\hline F-S1 & $68.8 \pm 3.2$ & $-68.8 \pm 3.2$ & - & $38.6 \pm 0.6$ & $1.37 \pm 0.058$ & $0 \%$ & $0.77 \pm 0.007$ & $0 \%$ \\
\hline F-U1 & $63.8 \pm 9.0$ & $-74.5 \pm 10.4$ & - & $35.8 \pm 5.5$ & $1.39 \pm 0.081$ & $1 \%$ & $0.78 \pm 0.051$ & $1 \%$ \\
\hline F-F1 & $61.9 \pm 1.0$ & $-49.3 \pm 0.9$ & $-215.5 \pm 3.9$ & $34.3 \pm 0.7$ & $1.37 \pm 0.021$ & $0 \%$ & $0.76 \pm 0.015$ & $-1 \%$ \\
\hline F-F2 & $68.9 \pm 3.7$ & $-56.1 \pm 3.7$ & $-245.8 \pm 15.7$ & $38.3 \pm 3.8$ & $1.53 \pm 0.052$ & $12 \%$ & $0.85 \pm 0.077$ & $10 \%$ \\
\hline
\end{tabular}




\subsection{Predictive Modeling of Prestressed NFC Tensile Mechanical Properties}

Using the material properties, specimen dimensions, and prestressing forces presented in Section 2.3 as inputs, the two theoretically derived analytical equations (Eq. 13 and Eq. 15) were used to predict the experimentally obtained tensile mechanical properties. Figure 4 shows a comparison between the theoretical and experimental results for the tensile strength-to-weight and stiffness-to-weight ratios of the prestressed NFC specimens. As indicated in Figure 4, all analytically predicted tensile mechanical properties were greater than those found via experimental data. While other authors have found that predicted tensile properties of unstressed, short-fiber NFCs using various rule of mixture models were also higher than experimental results, the higher predictions can be attributed to imperfect bonding between fibers and matrices [38]. The higher theoretical predictions in this study, however, were anticipated due to the well-known phenomenon of loss in prestressing upon prestressed fiber release during manufacture. The difference between experimental and theoretical results may be attributed to these and additional factors related to assumptions (i.e., linear elasticity), faults in the anchorage system, and additional prestress losses that may have occurred prior to (or during) experimental mechanical testing.

Given that the theoretical model provided fairly consistent overestimations of the prestressed tensile NFC behavior, an adjustment factor was employed not only to more accurately predict the tensile specific mechanical properties, but also to serve as a proxy for estimating prestress loss. Calibrating the results to within a ten percent (10\%) margin of error or less of the experimentally-obtained values, the adjustment factors that were used for tensile strength-to-weight and tensile stiffness-to-weight ratios were 0.87 and 0.95 , respectively. Incorporating each corresponding adjustment factor into Eq. 13 and Eq. 15 produced adjusted theoretical specific mechanical property values that are also shown in Figure 4. The theoretical predictions of mechanical properties using appropriate adjustment factors result in differences from experimental results of $0 \%, 0.4 \%$, and $4.6 \%$ in strength-to-weight ratios and $9.4 \%, 4.1 \%$, and $7.7 \%$ in stiffness-to-weight ratios for T-F1, T-F2, and T-F3, respectively. 


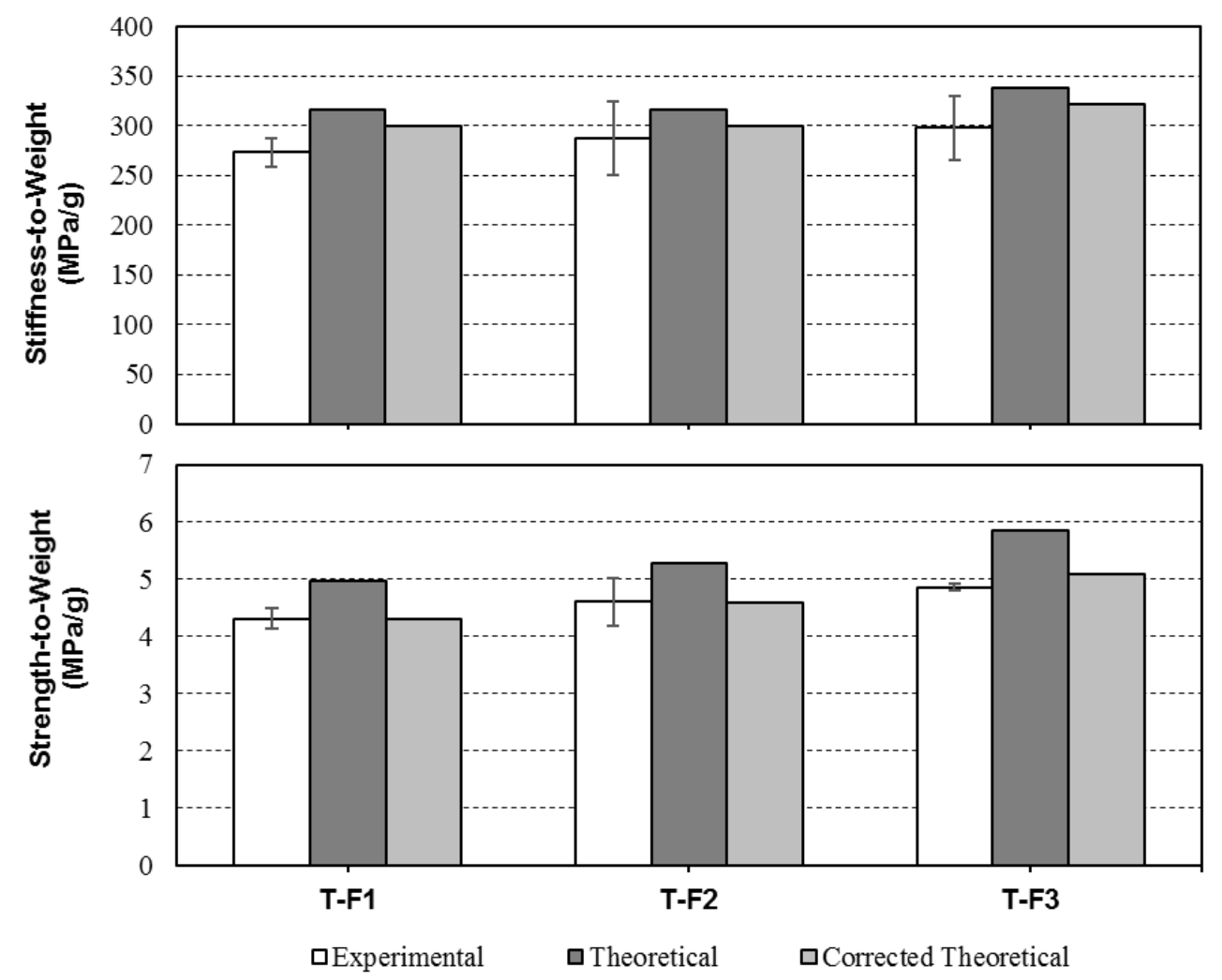

Figure 4. Comparison of experimentally and theoretically obtained composite tensile specific mechanical properties with and without adjustment factors to account for fiber prestress loss.

\section{Discussion}

The results obtained from this study suggest that fiber prestressing is a feasible technique that may be employed to more fully utilize the inherently high stiffness and strength of natural fibers in the design and fabrication of highperformance NFCs with high specific mechanical properties. This increase in specific mechanical properties translates to overall reductions in material quantities required for load-bearing applications. Minimizing material quantities (and reducing waste through additive manufacturing techniques) are inherently linked to economic and environmental benefits [39].

This approach will likely be most suitable for polymers with higher strengths in compression than in tension, such as the PLA material investigated herein. In addition, while its low $T_{\mathrm{g}}$ would limit its suitability for a number of load-bearing applications, this PLA matrix serves as a model system for other high-density polymeric matrices (e.g., HDPE) that are more suitable for construction-related applications.

Despite the positive results obtained in this study, several challenges exist for obtaining consistent behavior and mechanical properties of prestressed NFCs. Variation in fiber properties is often cited as a limitation of NFCs. 
However, as in this study, the variability can be reduced by using fiber strands rather than using continuous single fibers. The twisting of fiber into bundles and strands can reduce mechanical property variability, but may also reduce overall mechanical properties compared to single, continuous filaments of fiber. Relatedly, future advances in fiber processing and plant genetic technologies may contribute to improvements in consistency of natural fiber products. For example, Musialak, et al. [40] recently produced a flax plant using a transgenic approach with decreased pectin content and more efficiently extracted useable fibers from the stem tissue. Another challenge revealed in the present work was that prestress losses might occur during post-tensioning and anchoring of fiber strands. It is imperative that subsequent investigations consider the effectiveness of different prestressing anchorage techniques on minimizing prestress losses. The methodologies and results reported in these studies can inform predictions regarding the expected losses when implementing different anchorage systems and techniques.

In addition, a number of scientific and economic challenges may impede the replacement of synthetic, petroleumbased composites with biobased NFCs. Although the environmental benefits of biorenewable materials have been routinely demonstrated, fully biobased composites tend to exhibit low specific mechanical properties (as addressed herein), poor moisture resistance [41-43], and susceptibility to long-term viscoelastic deformation under sustained loads (creep) [44,45]. Relaxation of fibers and creep are especially critical in evaluating the long-term stability of prestressed-fiber NFCs. Relatedly, current research shows promising progress in improving the hygrophobicity of natural fibers through physical and chemical fiber treatments [46] and creep deformation [47]. However, biopolymer matrices (e.g., PLA, PHB) face current economic constraints since they are currently more costly to manufacture than their synthetic counterparts. The demand for biopolymers and bioplastics is expected to grow, and it is anticipated that the cost of these materials will become more economically competitive over time $[48,49]$.

In summary, opportunities exist to leverage this work in developing novel classes of high-performance NFCs. While this study investigated the mechanical performance of two natural fibers, namely jute and flax, one biopolymer (PLA), and two geometric arrangements, the proposed fiber prestressing technique is potentially viable for other geometries, natural fibers (e.g., silk, hemp, kenaf, abaca), and polymer matrices. Further experimental and theoretical research is needed, however, to evaluate the immediate and long-term performance of prestressed natural fibers in combination with other polymer matrix systems. 
Manuscript Submitted to:

Composites Part B: Engineering

\section{Conclusions}

This study investigated the effect of initial fiber prestressing on the specific tensile and flexural properties of natural fiber-reinforced polylactic acid (PLA) composite materials. The effect of fiber type (e.g., jute, flax), matrix crosssectional geometry, number of reinforcement strands, and level of initial fiber prestress on the tensile and flexural strength-to-weight and stiffness-to-weight ratios of PLA matrices were examined herein.

Experimental results confirm that utilizing additive manufacturing (3D printing) to produce more efficient structural shapes can improve the specific tensile and flexural mechanical properties of PLA composites and that these properties can be further improved via initial fiber post-tensioning. Given the superior tensile properties of flax compared to jute fiber strands, the flax-reinforced members with the greatest applied prestress force and fiber content exhibited the most notable improvement in specific mechanical properties. The data indicate increases of $116 \%$ and $62 \%$ for tensile strength- and stiffness-to-weight, respectively, and $12 \%$ and $10 \%$ for flexural specific strength- and rigidity-to-weight, respectively, compared to solid, unreinforced PLA specimens. In addition, an adjusted theoretical model derived to predict the improved tensile mechanical behavior of prestressed NFCs was validated by predicting experimental results with a margin of error of less than $10 \%$. Despite existing challenges associated with prestressed NFCs (e.g., fiber variability, anchorage systems, biopolymer economics), the results presented in this study suggest that prestressing continuous natural fiber reinforcement is a promising new paradigm for advancing the field of NFC science and engineering.

\section{Acknowledgments}

This research was made possible by the Department of Civil, Environmental, and Architectural Engineering (CEAE), the College of Engineering and Applied Sciences, and the CEAE Bridge-Term Fellowship at the University of Colorado Boulder with partial support from the National Science Foundation (Award \#1537194). This work represents views of the authors and not necessarily those of the sponsors.

\section{References}

1. Pietrini, M., Roes, L., Patel, M.K., Cheillini, E. (2007). “Comparative life cycle studies on poly(3hydroxybutyrate)-based composites as potential replacement for conventional petrochemical plastics.” Biomacromolecules, 8(7), pp. 2210-2218.

2. Baillie, C., Ed. (2004). Green Composites: Polymer Composites and the Environment, CRC Press, Cambridge, UK. 
3. Mohanty, A.K., M. Misra, and L.T. Drzal, (2002). "Sustainable bio-composites from renewable resources: opportunities and challenges in the green materials world.” J Polym Environ, 10(1), pp. 19-26.

4. Thomas, S., Pothan, L.A. (2009). Natural Fibre Reinforced Polymer Composites: From Macro to Nanoscale, Old City, Philadelphia, USA.

5. Ku, H., Wang, H., Pattarachaiyakoop, N., Trada, M. (2011). “A review on the tensile properties of natural fiber reinforced polymer composites." Compos Part B-Eng, 42, pp. 856-873.

6. Faruk, O., Bledzki, A.K., Fink, H.-P., Sain, M. (2012). "Biocomposites reinforced with natural fibers: 2000 2010.” Prog Polym Sci, 37, pp. 1552-1596.

7. Dittenber, D. B., \& GangaRao, H. V. (2012). "Critical review of recent publications on use of natural composites in infrastructure." Composites Part A: Applied Science and Manufacturing, 43(8), 1419-1429.

8. Bodros, E., Pillin, I., Montrelay, N., and Baley, C. (2007). “Could biopolymers reinforced by randomly scattered flax fibre be used in structural applications?" Compos Sci Technol, 67(3-4), pp. 462-470.

9. Srubar III, W.V., Pilla, S., Wright, Z.C., Ryan, C.A., Greene, J.P., Frank, C.W., Billington, S.L. (2012). "Mechanisms and impact of fiber-matrix compatibilization techniques on the material characterization of PHBV/oak wood flour engineered biobased composites." Compos Sci Technol; 72(6), pp. 708-715.

10. Alvarez, V.A., Fraga, A., and Vazquez, A. (2004). "Effects of the moisture and fiber content on the mechanical properties of biodegradable polymer-sisal fiber biocomposites.” J Appl Polym Sci, 91, pp. 4007-4016.

11.Netravali, A., Chabba, S. (2003). “Composites Get Greener.” Mater Today, 6(4), pp. 22-29.

12. Herrera-Franco, P., \& Valadez-Gonzalez, A. (2005). "A study of the mechanical properties of short natural-fiber reinforced composites." Comp Part B-Eng, 36(8), 597-608.

13.Lackey, E., Vaughan, J.G., Inamdar, K., Hancock, B. (2004). "Statistical characterization of pultruded composites with natural fiber reinforcements." COMPOSITES 2004: American Composites Manufacturers Association: Tampa, Florida.

14.Codispoti, R., Oliveira, D. V., Olivito, R. S., Lourenço, P. B., \& Fangueiro, R. (2015). "Mechanical performance of natural fiber-reinforced composites for the strengthening of masonry." Comp Part B-Eng, 77, 74-83.

15. Christian, S., Billington, S. (2011). "Mechanical response of PHB- and cellulose acetate natural fiber-reinforced composites for construction applications.” Compos Part B-Eng, 42(7), pp. 1920-1928. 
16. Bledzki, A.K., Jaszkiewicz, A. (2010). "Mechanical performance of biocomposites based on PLA and PHBV reinforced with natural fibres - A comparative study to PP.” Compos Sci Technol, 70(12), pp. 1687-1696.

17.Plackett, D., Andersen, T., Pedersenc, W., Nielsen, L. (2003). “Biodegradable composites based on 1-polylactide and jute fibres." Compos Sci Technol, 63(9), pp. 1287-1296.

18. Singh, B., Gupta, M. (2005). "Natural fiber composites for building applications." Natural Fibers, Biopolymers, and Biocomposites, A.K. Mohanty, M. Misra, and L.T. Drzal, Eds. CRC Press, Taylor \& Francis Group: Boca Raton, FL, pp. 261-290.

19. Billington, S.L., Srubar III, W.V., Miller, S.A., Michel, A.T. (2013). "Renewable biobased composites for civil engineering applications." Sustainable Composites and Advanced Materials. A. Netravali and C. Pastore, Eds. DESTech: Lancaster, PA, pp. 313-336.

20. Srubar III, W.V., Billington, S.L. (2013). “A micromechanical model for moisture-induced deterioration in fully biorenewable wood-plastic composites." Compos Part A-Appl S, 50, pp. 81-92.

21. Netravali, A., Huang, X., Mizuta, K. (2007). “Advanced 'Green' Composites.” Adv Compos Mater, 16(4), pp. 269-282.

22. Srubar, W. V. (2015). "An analytical model for predicting the freeze-thaw durability of wood-fiber composites." Comp Part B-Eng, 69, 435-442.

23. Symington, M., Banks, W.N., West, O.D., Pethrick, R.A. (2009). “Tensile testing of cellulose based natural fibers for structural composite applications.” J Compos Mater, 43(9), pp. 1083-1108.

24.Cheung, H.Y., Lau, K.-T., Ho, M.-P., Mosallam, A. (2009). "Study on the mechanical properties of different silkworm silk fibers." J Compos Mater, 43(22), pp. 2521-2531.

25. Avella, M., Martuscelli, E., Raimo, M. (2000). "Review of properties of blends and composites based on poly (3hydroxy) butyrate (PHB) and poly (3-hydroxybutyrate-hydroxyvalerate)(PHBV) copolymers.” J Mater Sci, 35(3), pp. 523-545.

26.Liao, Q., Tsui, A., Billington, S., Frank, C. (2012). "Extruded foams from microbial poly (3-hydroxybutyrate-co-3-hydroxyvalerate) and its blends with cellulose acetate butyrate." Polym Eng Sci, 52(7), pp. $1495-1508$.

27.Lee, S., Kareko, L., Jun, J. (2008). “Study of thermoplastic PLA foam extrusion.” J Cell Plast 44(4), p. 293-305. 
28. Motahhari, S., Cameron, J. (1999). "Fibre prestressed composites: improvement of flexural properties through fibre prestressing." J Reinf Plast Comp, 18(3), pp. 279-288.

29. Fazal, A., Fancey, K. S. (2014). “UHMWPE fibre-based composites: prestress-induced enhancement of impact properties." Compos Part B-Eng, 66, pp. 1-6.

30. Fazal, A., Fancey, K. S. (2014). "Performance enhancement of nylon/kevlar fiber composites through viscoelastically generated pre-stress.” Polym Composite, 35(5), pp. 931-938.

31. Schlichting, L.H., de Andrada, M.A., Vieira, L.C., Barra., G.M., Magne, P. (2010). "Composite resin reinforced with pre-tensioned glass fibers: influence of prestressing on flexural properties.” Dent Mater, 26(2), pp. 118-125.

32. Fancey, K. (2000). "The effects of fibre pre-stressing on the impact performance of composite laminates." $J$ Reinf Plast Comp, 19(15), pp. 1251-1266.

33. Bakis, C., Bank, L., Brown, V., Cosenza, E., Davalos, J., Lesko, J., Machida, A., Rizkalla, S., Triantafillou, T. (2002). "Fiber-reinforced polymer composites for construction: state-of-the-art review." J Compos Constr, 6, p. 73.

34.El-Hacha, R., Wight, R.G., Green. (2001). "Prestressed fibre-reinforced polymer laminates for strengthening structures." Prog Struct Eng Mat, 3, pp. 111-121.

35. Srubar III, W.V., Wright, Z.C, Tsui, A., Michel A.T., Billington, S.L., Frank, C.W. (2012). "Characterizing the effects of ambient aging on the mechanical and physical properties of two commercially available bacterial thermoplastics." Polym Degrad Stabil 97(10), pp. 1922-1929.

36. Martin, L.D., Perry, C.J., Eds. (2004). PCI design handbook: Precast and prestressed concrete. Vol. 1. Prestressed Concrete Institute.

37. Netravali, A.N., Pastore, C.M. (2014). Sustainable composites: fibers, resins and applications. DEStech Publications, Inc.

38. Venkateshwaran, N., Elayaperumal, A., \& Sathiya, G. K. (2012). "Prediction of tensile properties of hybridnatural fiber composites." Comp Part B-Eng, 43(2), 793-796.

39. Anastas, P.T., Zimmerman, J.B. (2003). "Peer Reviewed: Design Through the 12 Principles of Green Engineering.” Environ Sci Technol, 37(5), pp. 94A-101A.

40. Musialak, M., Wróbel-Kwiatkowska, M., Kulma, A., Starzycka, E., \& Szopa, J. (2008). Improving Retting of Fibre through Genetic Modification of Flax to Express Pectinases. Transgenic Res, 17(1), pp. 133-147. 
41.Espert, A., Vilaplana, F., Karlsson, S. (2004). "Comparison of water absorption in natural cellulosic fibres from wood and one-year crops in polypropylene composites and its influence on their mechanical properties." Compos Part A-Appl S, 35(11), pp. 1267-1276.

42. Almgren, K.M., Gamstedt, E.K., Berthold, F., Lindstrom, M. (2009). "Moisture uptake and hygroexpansion of wood fiber composite materials with polylactide and polypropylene matrix materials.” Polym Composite, 30(12), pp. 1809-1816.

43.Wang, W., Sain, M., Cooper, P.A. (2006). "Study of moisture absorption in natural fiber plastic composites." Compos Sci Technol, 66(3-4), pp. 379-386.

44. Alvarez, V., Kenny, J., Vázquez, A. (2004). “Creep behavior of biocomposites based on sisal fiber reinforced cellulose derivatives/starch blends." Polym Composite, 25(3), pp. 280-288.

45.Cyras, V., Martucci, J.F., Iannace, S., Vazquez, A. (2002). "Influence of the fiber content and the processing conditions on the flexural creep behavior of sisal-PCL-starch composites." J Thermoplast Compos, 15(3), pp. 253-265.

46. George, J., Sreekala, M., Thomas, S. (2001) “A review on interface modification and characterization of natural fiber reinforced plastic composites." Polym Eng Sci, 41(9), pp. 1471-1485.

47. Wong, S., Shanks, R., Hodzic, A. (2004). "Interfacial improvements in poly (3-hydroxybutyrate)-flax fibre composites with hydrogen bonding additives." Compos Sci Technol, 64(9), pp. 1321-1330.

48. Chanprateep, S. (2010). “Current trends in biodegradable polyhydroxyalkanoates.” J Biosci Bioeng, 110(6), pp. 621-632.

49. Van de Velde, K., Kiekens, P. (2002). "Biopolymers: overview of several properties and consequences on their applications," Polym Test, 21, pp. 433-442. 